\title{
Pleiotropic effects of the twin-arginine translocation system on biofilm formation, colonization, and virulence in Vibrio cholerae
} Lijuan Zhang ${ }^{\dagger 1}$, Zhaoqin Zhu ${ }^{\dagger 1}$, Huaiqi Jing1, Jingyun Zhang1, Yanwen Xiong ${ }^{1}$, Meiying Yan ${ }^{1}$, Shouyi $\mathrm{Gao}^{1}$, Long-Fei $\mathrm{Wu}^{2}$, Jianguo $\mathrm{Xu}^{1}$ and Biao Kan*1

Address: ${ }^{1}$ State Key Laboratory for Infectious Disease Prevention and Control, Department of Diarrheal Diseases, National Institute for Communicable Disease Control and Prevention, Chinese Center for Disease Control and Prevention. Beijing 102206, PR China and ${ }^{2}$ Laboratoire de Chimie Bacterienne, UPR9043, IBSM, CNRS, F-13402 Marseille Cedex 20, France

Email: Lijuan Zhang - zhanglijuan@icdc.cn; Zhaoqin Zhu - zhuzhaoqin@shaphc.org; Huaiqi Jing - jinghuaiqi@icdc.cn; Jingyun Zhang - jingyun1998@163.com; Yanwen Xiong - xiongyanwen@icdc.cn; Meiying Yan - yanmeiying2723357@hotmail.com; Shouyi Gao - gaoshouyi@icdc.cn; Long-Fei Wu - wu@ibsm.cnrs-mrs.fr; Jianguo Xu - xujianguo@icdc.cn; Biao Kan* - kanbiao@icdc.cn

* Corresponding author †Equal contributors

Published: 3I May 2009

BMC Microbiology 2009, 9:114 doi:10.1 186/147I-2180-9-1/4
Received: 17 August 2008

Accepted: 3I May 2009

This article is available from: http://www.biomedcentral.com/I47I-2/80/9/II4

(C) 2009 Zhang et al; licensee BioMed Central Ltd.

This is an Open Access article distributed under the terms of the Creative Commons Attribution License (http://creativecommons.org/licenses/by/2.0), which permits unrestricted use, distribution, and reproduction in any medium, provided the original work is properly cited.

\begin{abstract}
Background: The Twin-arginine translocation (Tat) system serves to translocate folded proteins, including periplasmic enzymes that bind redox cofactors in bacteria. The Tat system is also a determinant of virulence in some pathogenic bacteria, related to pleiotropic effects including growth, motility, and the secretion of some virulent factors. The contribution of the Tat pathway to Vibrio cholerae has not been explored. Here we investigated the functionality of the Tat system in $V$. cholerae, the etiologic agent of cholera.
\end{abstract}

Results: In $V$. cholerae, the $\operatorname{tat} A B C$ genes function in the translocation of TMAO reductase. Deletion of the $\operatorname{tat} A B C$ genes led to a significant decrease in biofilm formation, the ability to attach to HT-29 cells, and the ability to colonize suckling mouse intestines. In addition, we observed a reduction in the output of cholera toxin, which may be due to the decreased transcription level of the toxin gene in tat $A B C$ mutants, suggesting an indirect effect of the mutation on toxin production. No obvious differences in flagellum biosynthesis and motility were found between the tatABC mutant and the parental strain, showing a variable effect of Tat in different bacteria.

Conclusion: The Tat system contributes to the survival of $V$. cholerae in the environment and in vivo, and it may be associated with its virulence.

\section{Background}

In bacteria, transmembrane translocation, required for many newly synthesized proteins, can proceed through a number of routes depending on the nature of both the targeting signals and the folding state of substrates. In general, folded proteins are exported through the twin- arginine translocation (Tat) system [1]. Precursor proteins are directed to the Tat pathway by signal peptides that bear a characteristic consensus sequence, an unusually long S/T-R-R-x-F-L-K "twin-arginine" motif [2,3]. The most extensively characterized substrates for this pathway are trimethylamine $\mathrm{N}$-oxide (TMAO) reductase, a soluble 
periplasmic enzyme, and dimethyl sulfoxide (DMSO) reductase, a membrane-bound multisubunit enzyme, which have twin arginine signal sequences [1].

The Tat pathway is structurally and functionally related to the $\mathrm{pH}$-dependent protein import pathway of the plant chloroplast thylakoid membrane [2,4]. The Tat system of E. coli seems to operate with a similar mechanism as the Tat machinery of chloroplast thylakoids, as genes encoding HCF106 homologues are found in the complete genome sequences of some prokaryotes. Both pathways require three functionally distinct membrane-bound components, MttA, MttB, and MttC for HCF106, and TatA, TatB, and TatC for E. coli $[5,6]$. It is believed that TatB and TatC form a complex and are required for the recognition and binding of the twin-arginine signal peptide $[7,8]$. TatA is a homo-oligomer complex, which is recruited by the TatB-TatC complex and probably fulfills a channel function in the protein export process $[9,10]$. TatE, a TatA paralogue, functionally overlaps with TatA in E. coli $[1]$.

The Tat pathway is the major pathway required for the translocation of cofactor-containing enzymes participating in the respiratory and photosynthetic electron transport chains [4]. Indeed, the Tat system may be a determinant of virulence in some bacteria, as deletion of the Tat system may lead to pleiotropic defects, including growth, motility, and the secretion of some virulent factors in pathogenic bacteria. For example, the system is important for the virulence of pathogens including Pseudomonas aeruginosa [11,12], Agrobacterium tumefaciens [13], E. coli O157:H7 [14], Yersinia pseudotuberculosis [15], and Legionella pneumophila $[16,17]$. However, the contribution of the Tat pathway to the survival and virulence of Vibrio cholerae has not been reported.

$V$. cholerae is the causative agent of the diarrheal disease cholera. To date, there have been seven recorded pandemics of this severely dehydrating diarrheal disease. The ability of $V$. cholerae to survive the passage through the human gastric acid barrier, to colonize the human intestine with its pili and other outer membrane proteins and polysaccharides, and to secrete the cholera toxin (CT) are all crucial components of the bacterial life cycle [18]. Secretion of proteins is critical for the pathogenicity of the organism and for its survival in the natural environment. The genome of $V$. cholerae $E l$ Tor contains the tat $A B C$ operon in chromosome I and the tatA2 (tatE) gene in chromosome II [19]. To analyze the function and the involvement of the Tat system in the survival and virulence of $V$. cholerae, we constructed chromosomal in-frame deletion mutations in $t a t A B C$ and tatE. Our findings demonstrate that the $V$. cholerae tat $A B C$ genes function in the translocation of TMAO reductase. Moreover, we found that the mutation affected biofilm formation, attachment to HT29 cells, and colonization of suckling mouse intestines. The flagellum biosynthesis and motility, outer membrane integrity, and growth rate in normal cultures of Tat mutants were not affected. We also observed that the mutation impaired the transcription of the toxin gene, as well as CT production, although the ratio of secreted toxin to toxin stored in the cytoplasm was the same in the mutant and in the wild type strain. Overall, the Tat system is associated with the survival, as well as the virulence of V. cholerae.

\section{Methods}

\section{Bacterial strains, media, and growth conditions}

The bacterial strains and plasmids used in this study are listed in Table 1. The tatABC deletion mutant N169-dtat$\mathrm{ABC}$ strain was derived from the wild type $\mathrm{O} 1 \mathrm{El}$ Tor strain N16961 (Table 1). Both E. coli and V. cholerae cells were routinely grown at $37^{\circ} \mathrm{C}$ in Luria-Bertani broth (LB). For plate culture, LB was used with $1.5 \%$ agar (LBA). For the detection of CT production, $V$. cholerae were first grown under AKI conditions with sodium bicarbonate $(1.5 \%$ Bacto Peptone, $0.4 \%$ yeast extract, $0.5 \% \mathrm{NaCl}$ ) at $37^{\circ} \mathrm{C}$ for $4 \mathrm{~h}$, and the culture was then incubated overnight while shaking at $37^{\circ} \mathrm{C}[20]$. Antibiotics were used at the following concentrations: ampicillin, $100 \mu \mathrm{g} / \mathrm{ml}$; streptomycin, $100 \mu \mathrm{g} / \mathrm{ml}$; and chloramphenicol, $30 \mu \mathrm{g} / \mathrm{ml}$. The growth kinetics of the bacterial culture was measured spectrophotometrically with the optical density (OD) of the culture at $600 \mathrm{~nm}$. Complementarity of the E. coli tat mutants complemented by the $V$. cholerae tat genes was analyzed by anaerobic growth in M9-TMAO minimal media. The components of the M9-TMAO medium (for a final volume of 1 liter) in this study are listed below: $12.8 \mathrm{~g}$ $\mathrm{Na}_{2} \mathrm{HPO}_{4} ; 3.0 \mathrm{~g} \mathrm{KH}_{2} \mathrm{PO}_{4} ; 0.5 \mathrm{~g} \mathrm{NaCl} ; 1.0 \mathrm{~g} \mathrm{NH}_{4} \mathrm{Cl} ; 2 \mathrm{ml} 1$ $\mathrm{M} \mathrm{MgSO}_{4} ; 0.1 \mathrm{ml} 1 \mathrm{M} \mathrm{CaCl}_{2} ; 1 \mathrm{ml} 1 \%$ thiamine; $1 \mathrm{ml}$ molybdenum-selenium solution $(1 \mathrm{mM}$ potassium selenite and $1 \mathrm{mM}$ ammonium molybdate); $0.05 \mathrm{ml}$ Glycerol; $0.04 \mathrm{~g}$ TMAO. Strains were cultured at $37^{\circ} \mathrm{C}$ without shaking. The $\mathrm{OD}_{600}$ values were taken 22 hours after inoculation.

\section{Construction of the tat deletion mutants of $\mathrm{V}$. cholerae NI696I by allelic replacement}

To inactivate the tat $A B C$ genes of strain N16961, fragment A, which contains the $5^{\prime}$ portion of gene tatA and its upstream region, was amplified and digested with the enzymes EcoRI and KpnI and ligated between the EcoRI and KpnI sites of the pUC18 vector, generating the plasmid pT1 (Table 1). The 461 bp fragment B, which includes the 3 ' portion of gene $t a t C$ and its downstream 
Table I: Bacterial strains and plasmids used in this study

\begin{tabular}{|c|c|c|}
\hline Strains or plasmids & Relevant genotype and/or phenotype & Source or reference \\
\hline \multicolumn{3}{|l|}{ V. cholerae } \\
\hline NI696I & Serogroup OI, El Tor biotype & Our lab store \\
\hline NI69-dtatABC & tat $A B C$ deletion mutant from $\mathrm{N} 1696 \mathrm{I}$ & This study \\
\hline NI696I(pBAD24) & NI696I transformed with vector pBAD24 & This study \\
\hline NI69-dtatABC(pBAD24) & NI69-dtatABC transformed with pBAD24 & This study \\
\hline NI69-dtatABC-cp & NI69-dtatABC complemented with pBAD-TatABC & This study \\
\hline NI69-dtatABC-BCcP & NI69-dtatABC complemented with PBAD-TatBC & This study \\
\hline NI69-dtatE & tatE deletion mutant from $\mathrm{N} 1696 \mathrm{I}$ & This study \\
\hline NI69-dtatABCE & tat $A B C$ and tatE double deletion mutant from NI696I & This study \\
\hline NI69-dtatABCE-BCcP & NI69-dtatABCE complemented with pBAD24 carrying tatBC & This study \\
\hline NI69-dtatB & tatB deletion mutant from $\mathrm{N} 1696 \mathrm{I}$ & This study \\
\hline NI69-dtatC & tatC deletion mutant from N1696I & This study \\
\hline \multicolumn{3}{|l|}{ E. coli } \\
\hline SMIO $\lambda$ pir & thi thr leu tonA lacY supE recA::RP4-2-Tc::Mu Km & 21 \\
\hline JARVI6A (dtatAE) & tatA and tatE double deletion mutant from JARVI6A & 34 \\
\hline MCMTAA(dtatB) & tatB::Kan mutant from MCMTAA & 34 \\
\hline BILKOA (dtatC) & tatC deletion mutant from BILKOA & 34 \\
\hline DADEA (dtatABCDE) & tat $A B C D$ and tatE double deletion mutant from DADEA & 34 \\
\hline \multicolumn{3}{|l|}{ Plasmids } \\
\hline pCVD442 & Suicide vector, ori $\mathrm{R} 6 \mathrm{~K}, \mathrm{Amp} \mathrm{p}^{\mathrm{r}}$, sacB & 21 \\
\hline pDSI 32 & Suicide vector, ori $\mathrm{R} 6 \mathrm{~K}$, from pCVD442, $\mathrm{Cm}^{\mathrm{r}}$, sacB & 22 \\
\hline PTI & $7 / 4$ bp EcoRl-Kpnl fragment $A$ of tatA cloned into pUCI 8 & This study \\
\hline PT2 & $46 I$ bp Xbal-Pstl fragment B of tatC cloned into pTI & This study \\
\hline PT3 & 801 bp fragment of cat cloned into Smal site of PT2 & This study \\
\hline РCT4 & I,976 bp fragment of 'A-cat-B' cloned into Sphl site of pCVD442 & This study \\
\hline pUCI8C & intact tatABC and upstream fragment cloned between EcoRI and Sacl site of pUCI8 & This study \\
\hline pBAD24 & pMBI-derived plasmid, Ampr, araBAD & 23 \\
\hline PTatABC-30I & intact tat $A B C$ fragment of $E$. coli cloned into pBAD24 & This study \\
\hline PBAD-TatABC & intact tat $A B C$ fragment of $\mathrm{N} 1696 \mathrm{I}$ cloned into pBAD24 & This study \\
\hline PBAD-TatBC & tatBC fragment of N1696I cloned into pBAD24 & This study \\
\hline PBAD-TatE & tatE fragment of $\mathrm{N} 1696 \mathrm{I}$ cloned into pBAD24 & This study \\
\hline
\end{tabular}

region, was amplified and ligated between the XbaI and Pst I sites of the vector pT1, generating the plasmid pT2 (Table 1).

The chloramphenicol gene (cat) was amplified and ligated into the SmaI site of pT2, generating the plasmid pT3. To create a deletion-insertion allele, pT3 was digested with the enzyme SphI, and a 1976 bp fragment of "A-cat-B" was gel purified and subsequently ligated into the SphI site of pCVD442 [21]. The resulting recombinant plasmid, pCT4, was then transferred by conjugation from E. coli SM10 $\lambda$ pir [21] into the V. cholerae strain N16961. Mutant strains were selected on chloramphenicol plates with sucrose but without $\mathrm{NaCl}$ at $30^{\circ} \mathrm{C}$, by $\mathrm{SacB}$ counter-selection strategy. The mutant strain, N169-dtatABC, which contains a mutation in tat $A B C$, was confirmed by PCR and sequencing. The intact sequences of the neighboring genes in the upstream and downstream regions of tat $A B C$ were also confirmed.

To complement the tat $A B C$ deletion, a DNA fragment containing the $\operatorname{tat} A B C$ gene and a 206 bp upstream frag- ment was amplified. The resulting fragment was then ligated into the EcoRI/SacI digested vector, pBAD24. After transformation of the recombinant plasmid into N169dtatABC cells, the complemented strain N169-dtatABC-cp was obtained.

To test the functions of different genes of the Tat system, we constructed four more chromosomal in-frame deletion mutants (N169-dtatB, N169-dtatC, N169-dtatE and N169-dtatABCE, see Table 1) by allelic replacement and SacB counter-selection strategy with the suicide plasmid pDS132 [22], and two other complemented strains (N169-dtatABC-BCcp and N169-dtatABCE-BCcp, see Table 1) with the expression plasmid pBAD24 [23], according to the strategies used above (in deletion mutation through allelic replacement with pDS132, the marker of cat gene was not used any more). The primers used to construct the mutants and complementary strains were listed in the Additional file 1. Reverse transcription-PCR were used to detect the gene transcription in these mutants and complement strains in LB culture. 


\section{Enzymatic assay}

The test for trimethylamine- $\mathrm{N}$-oxide (TMAO) reductase activity is based on the oxidation of reduced methyl viologen, coupled to the reduction of TMAO to trimethylamine [24,25]. To analyze the cellular distribution of TMAO reductase, periplasm and spheroplasts were prepared by the lysozyme-EDTA-cold osmoshock method [25]. The prepared fractions of periplasm and cytoplasm were confirmed by using western blotting, with the antibodies to $\beta$-lactamase and GroEL (Abcam). Strain N16961 was transformed with plasmid pBAD24 to express $\beta$-lactamase and obtain ampicillin resistance. IRDye $800 \mathrm{CW}$ goat anti-mouse IgG (LI-COR Bioscience) was used as the second antibody. The bands were scanned with the Odyssey Infrared Imaging Systems (LI-COR Bioscience). The mixture was then resolved ret by $12 \%$ nondenaturing polyacrylamide gel (polyacrylamide gel without denaturant SDS) electrophoresis, and TMAO reductase activity was subsequently visualized on nondenaturing polyacrylamide gels. For this purpose, the gels were placed in a nitrogen atmosphere in a plate containing $25 \mathrm{ml}$ of potassium phosphate buffer $(100 \mathrm{mM}, \mathrm{pH}$ 6.5), $0.5 \mathrm{ml}$ of $0.22 \mathrm{~g} / \mathrm{ml}$ methyl viologen solution, and a small amount of $\mathrm{Na}_{2} \mathrm{~S}_{2} \mathrm{O}_{4}$ dissolved in $0.01 \mathrm{M} \mathrm{NaOH}$. The gels, uniformly colored blue by reduced methyl viologen, were then incubated in $25 \mathrm{ml}$ of phosphate buffer (100 $\mathrm{mM}, \mathrm{pH} 6.5$ ) supplemented with $0.5 \mathrm{ml}$ of $0.25 \mathrm{~g} / \mathrm{ml}$ TMAO solution. The resulting clear bands on the blue background indicate the presence of active TMAO reductase in the gel.

\section{Growth assessment of strains in M9-TMAO media}

The overnight cultures of different tat genes deletion mutants and complement strains (listed in Table 1) and the wild type strain N16961 were diluted 1:100 and incubated in fresh $\mathrm{LB}$ to $\mathrm{OD}_{600}$ more than 0.8 . Then the culture of each was adjusted with LB to OD600 of 0.8 . Then they were then diluted 1:100, and $50 \mu$ l of each culture was transferred into M9-TMAO media and subsequently cultured statically at $37^{\circ} \mathrm{C}$ in the anaerobic jar (Oxoid). The vacuum extractor was used to extract the air in the anaerobic jar to lower atmospheric pressure (-10 millimeters of mercury), and then $\mathrm{H}_{2}$ and $\mathrm{CO}_{2}$ were inflated to normal atmospheric pressure. The culture was grown for $24 \mathrm{~h}$, and then the $\mathrm{OD}_{600}$ of each culture was determined.

\section{Motility assay}

Motility of N16961 and N169-dtatABC cells was tested on $0.3 \%$ minimal motility agar containing $1 \%$ peptone and $0.5 \% \mathrm{NaCl}(\mathrm{wt} / \mathrm{v})$. Briefly, cell cultures grown in LB broth overnight at $37^{\circ} \mathrm{C}$ were diluted 1:1000. Cell cultures were then grown to $\mathrm{OD}_{600} 0.2$. Subsequently, each strain was inoculated onto the surface of the motility U type tubes. Motility was examined after $12 \mathrm{~h}$ and $16 \mathrm{~h}$ of incubation at $37^{\circ} \mathrm{C}$. The percentage of the length of growth diffusion in the agar of the mutant strain N169-dtatABC compared to the wild type strain was calculated. At least five independent motility assays were carried out for each strain and condition.

\section{Outer membrane integrity assay}

We detected the outer membrane integrity according to the method of reference [26]. The wild type strain N16961 and the Tat mutant strain N169-dtatABC were cultured overnight and then diluted 1:100 into fresh LB and grown to $\mathrm{OD}_{600} 0.4$. Five milliliters of fresh $\mathrm{LB}$ was added into each tube, and SDS or Gentamicin (Get) was added to final concentrations of 0 to $2.5 \%$ and 0 to $500 \mu \mathrm{g} / \mathrm{ml}$, respectively. Experiments were performed in triplicate for N16961 and Get. After SDS or Get addition, all tubes were grown at $37^{\circ} \mathrm{C}$ for $3 \mathrm{~h}$ at $250 \mathrm{rpm}$, after which the $\mathrm{OD}_{600}$ of each culture tube was measured. We defined the $\mathrm{OD}_{600}$ of the wild type strain cultured in LB without SDS and Get as $100 \%$. The $\mathrm{OD}_{600}$ values of the other conditions were converted to the percentage of $\mathrm{OD}_{600}$ of the wild type strain cultured in LB without SDS and Get. To determine whether the outer membrane of the mutants was destroyed, the results are plotted as SDS or Get dilution on the $\mathrm{X}$-axis and $\mathrm{OD}_{600}$ percentage on the Y-axis [26].

\section{Flagellum extraction and quantification}

Bacterial cells were recovered from a $600 \mathrm{ml}$ LB culture of $\mathrm{N} 16961$ and N169-dtatABC incubated overnight at $37^{\circ} \mathrm{C}$ and then centrifuged for $5 \mathrm{~min}$ at $10,000 \mathrm{~g}$. The pellets were resuspended in PBS buffer and vortexed for $5 \mathrm{~min}$, with a $30 \mathrm{~s}$ interval after $2.5 \mathrm{~min}$. The supernatants were centrifuged again for $10 \mathrm{~min}$ at $15,000 \mathrm{~g}$. After recovery of the supernatants, SDS was added $(0.1 \% \mathrm{wt} / \mathrm{v})$. The flagellum pellets were obtained by centrifugation at 100,000 g for $2 \mathrm{~h}$ at $4{ }^{\circ} \mathrm{C}$. The supernatants were removed, and the flagellum filaments were resuspended in $50 \mu$ l of HEPES buffer (10 mM HEPES, $10 \mu \mathrm{M}$ EDTA pH 8.0, $200 \mu \mathrm{M}$ $\left.\mathrm{CaCl}_{2}\right)$. Before the flagella were detached from the N16961 and N169-dtatABC cells, we calculated the wet weight of each cell type. To quantify the extracted flagellum proteins, the flagellum extracts from N16961 and N169-dtatABC cells were equated by the wet weight of the collected cells. The concentration of the flagellum extraction was quantified with the BSA standard curve by Bradford assay. Purity of the flagellum preparations was assessed by denaturing SDS-PAGE. Flagellum extraction and quantification were performed in triplicate.

\section{Biofilm formation assay}

In a quantitative biofilm formation assay, both primary attachment and accumulation in multilayered cell clusters, which together lead to biofilm formation, can be measured by altering the incubation time of the bacteria. Biofilm assays were done according to the protocol of Loo et al. [27] with minor modifications. Briefly, overnight cultures of N16961 and dtat-N169 cells were diluted 1:100 into fresh $\mathrm{LB}$ medium and grown at $37^{\circ} \mathrm{C}$ to $\mathrm{OD}_{600}$ 
0.5 , both under aerobic and anaerobic conditions. The cultures were then again diluted 1:100 into fresh LB, and $200 \mu \mathrm{l}$ of the cell suspension was placed into separate wells of a 96-well (flat bottom) cell culture plate (Costar 3595, Corning). Wells containing fresh growth medium were used as negative controls. Plates were incubated at $37^{\circ} \mathrm{C}$ under both aerobic and anaerobic conditions for 6 to $72 \mathrm{~h}$. The artificial anaerobic condition was generated by an anaerobic jar (Oxoid) where the plates were incubated. The vacuum extractor was used to extract the air in the anaerobic jar to lower atmospheric pressure (-10 millimeters of mercury), and then $\mathrm{H}_{2}$ and $\mathrm{CO}_{2}$ were inflated to normal atmospheric pressure. Before biofilm quantification, growth was assessed by measuring the absorbance of cultures in the wells at $595 \mathrm{~nm}$ using GENios (TECAN). For this purpose, media and unattached bacterial cells were decanted from the wells after 5 min of agitation, and the remaining planktonic or loosely bound cells were removed by gentle rinsing with $200 \mu \mathrm{l}$ of sterile distilled water. The plates were then blotted on paper towels and air-dried. The adhering bacteria were stained with $225 \mu \mathrm{l}$ of $0.1 \%$ crystal violet for $15 \mathrm{~min}$ at room temperature. After two rinses, each with $250 \mu$ of water, the bound dye was extracted from the stained cells using $250 \mu \mathrm{l}$ of $99 \%$ ethanol. The plates were then agitated for $15 \mathrm{~min}$ to fully release the dye. Biofilm formation was quantified by measuring the absorbance of the rinsed solution at 595 $\mathrm{nm}$ with GENios. The data were obtained in triplicate tests, and seven wells were measured for each strain (N16961 and N169-dtatABC) and in each test.

\section{Cell culture and bacterial attachment assay}

HT-29 (human colon adenocarcinoma) cells were grown in Dulbecco modified Eagle medium supplemented with equal volumes of F-12 nutrient mixture (Ham) powder (DMEM/F12 culture), 5\% fetal bovine serum, and 1\% Pen-Strep (GibcoBRL) under $5 \% \mathrm{CO}_{2}$ [28]. The cultures of N16961 and N169-dtatABC cells were adjusted to the same optical density at $600 \mathrm{~nm}$ (1.0). A confluent HT-29 cell monolayer was infected with the bacterial mixture (1 mL LB containing $10^{6}$ CFU of N16961 and $10^{6}$ CFU N169dtatABC) and incubated at $37^{\circ} \mathrm{C}$. For quantification of the attached bacteria, a 6 -well cell culture plate was used, the monolayers and attached bacteria were washed three times with PBS and incubated for $30 \mathrm{~min}$ in a $1 \%$ Triton $\mathrm{X}-100$ solution. The resulting bacterial suspensions were appropriately diluted with LB and plated onto plates containing thiosulfate citrate bile salts sucrose (TCBS) agar and TCBS agar supplied with $15 \mu \mathrm{g} / \mathrm{ml}$ chloramphenicol. The competitive attachment ratio was calculated according to the following formula (the ratios were from 6 wells of repeat):

Competitive attachment ratio = (average number of colonies on TCBS plates - average number of colonies on chloramphenicol plates)/average number of colonies on chloramphenicol TCBS plates.

For the immunofluorescence assay, glass slides were placed in each well of a six-well plate (Corning) before the wells were inoculated with HT-29 cells. An HT-29 confluent monolayer was infected with $1 \mathrm{ml}$ of N16961, N169dtatABC, or N169-dtatABC-cp ( $10^{6} \mathrm{CFU}$ each) and incubated at $37^{\circ} \mathrm{C}$ for $4 \mathrm{~h}$. The monolayers and attached bacteria were washed three times with PBS. Cells were then fixed using $2 \%$ polyformaldehyde. The monoclonal antibodies against the $V$. cholerae serogroup $\mathrm{O} 1$ were added into cells. The plates were incubated at $37^{\circ} \mathrm{C}$ for $1 \mathrm{~h}$ and washed three times with PBS. FITC-labeled IgG1 (1:1500 dilution in PBS) was added to each well. The plates were incubated at $37^{\circ} \mathrm{C}$ for $30 \mathrm{~min}$ and then inspected with the confocal microscope (LSM510META, Zeiss).

\section{Suckling mouse intestinal colonization assay}

Suckling mouse intestines were infected with $V$. cholerae as described by Baselski and Parker [29] with slight modifications. Briefly, the overnight cultures of N16961 and N169-dtatABC cells were diluted in LB to an equal $\mathrm{OD}_{600}$. Five- to 7-day-old suckling Balb/C mice (separated from their mothers) were intragastrically inoculated with 100 $\mu \mathrm{l}$ of N16961 and N169-dtatABC cultures. The bacterial titers of each inoculum were determined by plating serial dilutions of the inocula. Infected mice were kept at $24^{\circ} \mathrm{C}$ in the absence of their mothers. Mice were sacrificed $16 \mathrm{~h}$ after inoculation. Whole intestines were removed, cut into short segments, and then mechanically homogenized in $4.5 \mathrm{ml}$ of LB containing 20\% (v/v) glycerol. Serial dilutions were plated onto TCBS agar (to isolate N16961 and N169-dtatABC) and TCBS agar supplemented with $50 \mu \mathrm{g} /$ ml chloramphenicol (to isolate N169-dtatABC) to count the $V$. cholerae CFU per dilution. The attachment competitive ratio was calculated according to the same formulation as that of the HT-29 cell attachment model. Twelve suckling mice were used for the repeat of attachment assay.

\section{Assay of CT production by GMI-ELISA}

CT production in culture supernatants was estimated in $V$. cholerae strains (N16961, N169-dtatABC, and N169-dtatABC-cp) incubated with AKI media (containing 1.5\% Bacto peptone, $0.4 \%$ yeast extract-Difco, $0.5 \% \mathrm{NaCl}$ and $\left.0.3 \% \mathrm{NaHCO}_{3}\right)$, cultured at $37^{\circ} \mathrm{C}$ for $4 \mathrm{~h}$ in a stationary test tube and then for $16 \mathrm{~h}$ in a shaken flask, and measured by GM1-ELISA [30]. In our study, the medium used for all cultures was AKI with $0.3 \%$ sodium bicarbonate. To determine CT production, the strains incubated under static conditions for $4 \mathrm{~h}$ at $37^{\circ} \mathrm{C}$ were poured into flasks with a 20 -fold greater volume than the tubes to continue growth at $37^{\circ} \mathrm{C}$ for $18 \mathrm{~h}$ with shaking at $220 \mathrm{rpm}$. All culture supernatants were concentrated 10-fold with 
PEG6000. A standard curve was generated using the purified B subunit of CT. As a second antibody, the monoclonal antibody against the B subunit of CT was added. Color intensity was measured at $492 \mathrm{~nm}$ in an ELISA reader (Bio-Rad). Three independent triplicate repeats were done for each strain.

\section{Transcription analysis of the ctxB gene in N/696I and NI69-dtatABC cells}

The overnight cultures of N16961 and N169-dtatABC cells were re-cultured to $\mathrm{OD}_{600} 1.0$ with fresh $\mathrm{LB}$, and then 1:100 dilutions were transferred into AKI medium. The medium used for all cultures was AKI complemented with $0.3 \%$ sodium bicarbonate. To determine the $\operatorname{ct} x B$ transcription levels, the strains incubated under still conditions for $4 \mathrm{~h}$ at $37^{\circ} \mathrm{C}$ were poured into flasks with a 20fold greater volume than the tubes to continue growth at $37^{\circ} \mathrm{C}$ for $18 \mathrm{~h}$ with shaking at $220 \mathrm{rpm}$. The RNeasy Mini Kit (Qiagen) was used to extract total RNA from $1 \mathrm{ml}$ of bacterial cultures. The RNase-free DNase set Kit (Qiagen) was used to eliminate DNA. RNA samples were diluted to $1 \mathrm{ng} / \mu \mathrm{l}$ in order to obtain the template for RT-PCR after quantification. Primers 5'-CGC ATG AGG CGT TTT ATT ATT C-3' and 5'-AAA GCG ATT GAA AGG ATG AAG G-3' were used to amplify $c t x B$ gene. The housekeeping gene thyA (primers 5'-ACA TGG GAC GCG TGT ATG G-3' and 5'-ATA TGA CCA CCA TCA GGC TTA GC-3') and 16SrDNA (primers 5'-TTG ACA TCC AGA GAA TCT AGC GG3' and 5'-TTA ACC CAA CAT TTC ACA ACA CGA-3') were selected as the references. RNA extraction and RT-PCR quantification were done in triplicate for each strain. 2$\Delta \Delta \mathrm{Ct}$ method was used to calculate the Ct difference of $c t x B$ between N16961 and N169-dtatABC, with the existence of the control genes. $\Delta \Delta \mathrm{Ct}=\left(\mathrm{Ct}_{\mathrm{N} 169-\mathrm{dtat} \mathrm{ABC}(\mathrm{ctxB})}-\mathrm{Ct}_{\mathrm{N} 169-\mathrm{dtat}-}\right.$
$\mathrm{ABC}($ reference) $)-\left(\mathrm{Ct}_{\mathrm{N} 16961(\mathrm{ctxB})}-\mathrm{Ct}_{\mathrm{N} 16961 \text { (reference) }}\right)$, in it $\mathrm{Ct}_{\mathrm{N} 169 \text { - }}$ dtatABC(reference) and $\mathrm{Ct}_{\mathrm{N} 16961 \text { (reference) }}$ mean the average of $\mathrm{Ct}$ values of thyA or 16s-rDNA gene of the N169-dtatABC and $\mathrm{N} 16961$ samples respectively, $\mathrm{Ct}_{\mathrm{N} 169-\operatorname{dtatABC}(\operatorname{ctxB})}$ and $\mathrm{Ct}_{\mathrm{N16961(ctxB)}}$ mean the average of $\mathrm{Ct}$ values of $\operatorname{ctxB}$ gene of the N169-dtatABC and N16961 samples respectively. 2$\triangle \Delta \mathrm{Ct}$ means the times of $c t x B$ transcription of N169-dtatABC compared to N16961.

\section{Results}

\section{V. cholerae has a functional Tat system}

The genetic structure and composition of the tat genes vary in different bacteria [31]. We analyzed the genome sequence of $V$. cholerae $\mathrm{N} 16961$ and found the genes tat $A$, tat $B$, and tat $C$ in chromosome I, and tat $A 2$ in chromosome II (VC0086 and VCA0533 were annotated as tatA and tatA2, respectively). These genes encode four proteins with a high degree of homology to the E. coli K-12 tat genes, ranging from 43.3 to $65.7 \%$ amino acid identity (Fig. 1). In addition to the tat genes, the cytochrome c551 peroxidase gene (VC0089) was found in the downstream region of the tat $A B C$ operon, and the ubiquinone biosynthesis protein Aarf gene (VC0085) was found in the upstream region of the tat $A B C$ operon. No homologue of the previously designated tatD of $E$. coli was detected in the tat $A B C$ operon for $V$. cholerae. The tat 22 gene on chromosome II has a high degree of homology to both $E$. coli genes tatA (36.7\%) and tatE (38.2\%) (Fig. 1). Due to the higher level of sequence identity of the $V$. cholerae tatA2 to E. coli tatE than to E. coli tatA (Fig. 1), and due to its distant location from tat $A B C$, tatA2 appears to be most similar to the $E$. coli tatE gene. Therefore, we renamed tatA2 as $V$. cholerae tatE.

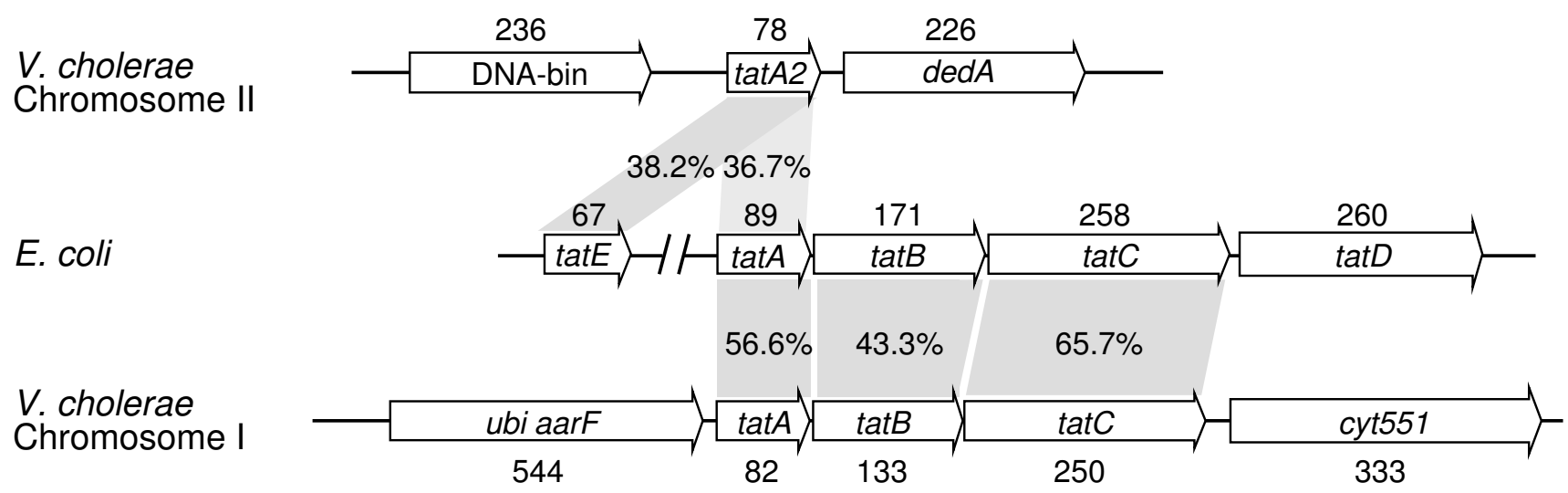

Figure I

Sketch of the chromosomal regions encoding tat genes in $E$. coli and $\mathbf{V}$. cholerae. This sketch compares the structure of the tat gene clusters and the amino acid sequences between the V. cholerae El Tor strain NI696I and E. coli. The numbers near the arrowheads of the ORFs signify the length in amino acids, and the percentages indicate the amino acid identity of the compared genes connected with grey squares. 
To determine whether the Tat mutants still have a functional Tat system, a series of Tat gene mutants of the $V$. cholerae strain N16961 was constructed to determine their growth in the M9-TMAO media. By using reverse transcription-PCR assay, transcription of corresponding tat genes in all the mutants and complement mutants were confirmed, each of the deleted genes were negative in reverse transcription-PCR, and all the complemented genes became positive in each complement strain (data not shown). In E. coli, Tat mutants were unable to grow anaerobically with either dimethyl sulfoxide or TMAO as the sole terminal electron acceptor, unless complemented by functional tat genes, due to the negligible levels of periplasmic TMAO reductase $[32,33]$. The $V$. cholerae mutants included deletion mutants of tatABC (N169-dtatABC), tatABCE (N169-dtatABCE), tatB (N169-dtatB), tatC (N169-dtatC) and tatE (N169-dtatE) (Table 1). The mutant tatA (N169-dtatABC-BCcp) was obtained by complementation with pBAD-TatBC into strain N169-dtat$\mathrm{ABC}$, and the double mutant strain (N169-dtatABCEBCcp) of tat $A$ and tatE was obtained by complementation with pBAD-TatBC into strain N169-dtatABCE (Table 1). We found that the wild type $V$. cholerae strain N16961 and MG1655, the E. coli strain derived from K-12, could grow in in M9-TMAO media, whereas the mutants N169-dtat$\mathrm{ABC}$ and N169-dtatABCE could not grow after being cultured at $37^{\circ} \mathrm{C}$ for $24 \mathrm{~h}$ (Fig. 2). However, when pBADTatABC was restored into the mutants N169-dtatABC and pBAD-TatABC was restored into N169-dtatABCE, the complementary strains could grow well in the M9-TMAO media, indicating that the $\operatorname{tat} A B C$ cluster is essential in the function of the Tat system. N169-dtatE and N169-dtatABC-BCcp could grow in M9-TMAO media, although the $\mathrm{OD}_{600}$ values of these strains were slightly lower than that of N16961 (Fig. 2). In addition, the $\mathrm{OD}_{600}$ of N169-dtatB and N169-dtatC was noticeably lower than that of N16961 in M9-TMAO media (Fig. 2). Therefore, the tatB and $t a t C$ genes appear to be necessary for the $V$. cholerae Tat system, and tat $A$ and tatE may functionally overlap in V. cholerae.

We also transformed pBAD-TatABC and pBAD-TatE, plasmids containing $V$. cholerae-derived tat $A B C$ and tatE, into the E. coli tat gene mutants [34] to assess if TatA or TatE is essential to Tat system. As shown in Table 2, pBAD-Tat$\mathrm{ABC}$ restored the growth of $E$. coli tat $A E$, tatB, tat $C$, and tat$A B C D E$ mutants in M9-TMAO media, whereas pBAD-TatE only restored the growth of the tat $A E$ mutant. Therefore, $V$. cholerae tat genes can replace their E. coli counterparts to reconstitute a heterologous functional Tat system. Here it was also shown that tatE, located on chromosome II, may functionally overlap tatA in $V$. cholerae. The functionality of the Tat system was also confirmed by the subcellular distribution of TMAO reductase activity in the wild type strain N16961, the tatABC mutant strain N169-dtat-
ABC, and strain N169-dtatABC-cp, N169-dtatABC restored with pBAD-TatABC. The prepared fractions of periplasm and cytoplasm were confirmed with the control of western blot assay, using the antibodies to $\beta$-lactamase and GroEL. It was shown that $\beta$-lactamase was predominantly in the extractd periplasmic fraction, while GroEL was mainly in the extracted cytoplasmic fraction [see Additional file 2]. As anticipated, the TMAO reductase activity was detected in the periplasm of the wild type strain N16961 and N169-dtatABC-cp, but it accumulated in the cytoplasm of N169-dtatABC (Fig. 3).

\section{Growth and morphology of the tatABC mutant}

The E. coli Tat system is required for the translocation of amidases, and tat mutants display impaired cell division and chain-forming phenotypes [26]. We found that both the wild type strain and the tat $A B C$ mutant N169-dtat $A B C$ exhibited normal vibrioid morphology (Fig. 4A and 4B), except that some of mutant cells showed the curved or contorted form. The chains of bacterial cells of the mutant were not observed. Therefore, the Tat protein translocation system did not seem to obviously affect the cell morphology of N16961. Under both aerobic and anaerobic conditions at $37^{\circ} \mathrm{C}$, the mutant strain N169-dtatABC did not show any obvious growth deficiencies (data not shown); hence, the Tat protein translocation system did not seem to affect its growth and division.

Like the wild type strain, the tat $A B C$ mutant colonies were smooth and moist in fresh LBA medium for the first 7 days at room temperature. Interestingly, in contrast to the wild type strain, some of N169-dtatABC colonies started to shift to the rugose (wrinkled) phenotype 7 days after inoculation at room temperature, and all the colonies of the mutant shifted to the rugose phenotype 16 days after inoculation, while colonies of the wild type strain were still smooth (Fig. 4E and 4F). Therefore, in contrast to the wild type strain, the tat $A B C$ mutant was easier to shift to the rugose phenotype at room temperature.

\section{Outer membrane integrity assay}

To test the integrities of the outer membrane of $V$. cholerae tat mutants, we quantified the sensitivity of the mutants with respect to the hydrophobic drug Get and the detergent SDS, based on the concentration of Get or SDS that is required to kill $50 \%$ of the cells in liquid culture (LD50). LB without SDS or Get was used as the negative control. We compared the $\mathrm{OD}_{600}$ of the wild type strain and the mutant strains cultured in LB with different dilutions of SDS or Get, and did not find any changes of $\mathrm{OD}_{600}$ and LD50 when compared the wild type strain N16961 with the different tat gene mutants, therefore we did not find any integrity defect in the Tat mutants, including N169-dtatABCE, N169-dtatABC, N169-dtatB, N169-dtatC, and N169-dtatE (data not shown). 


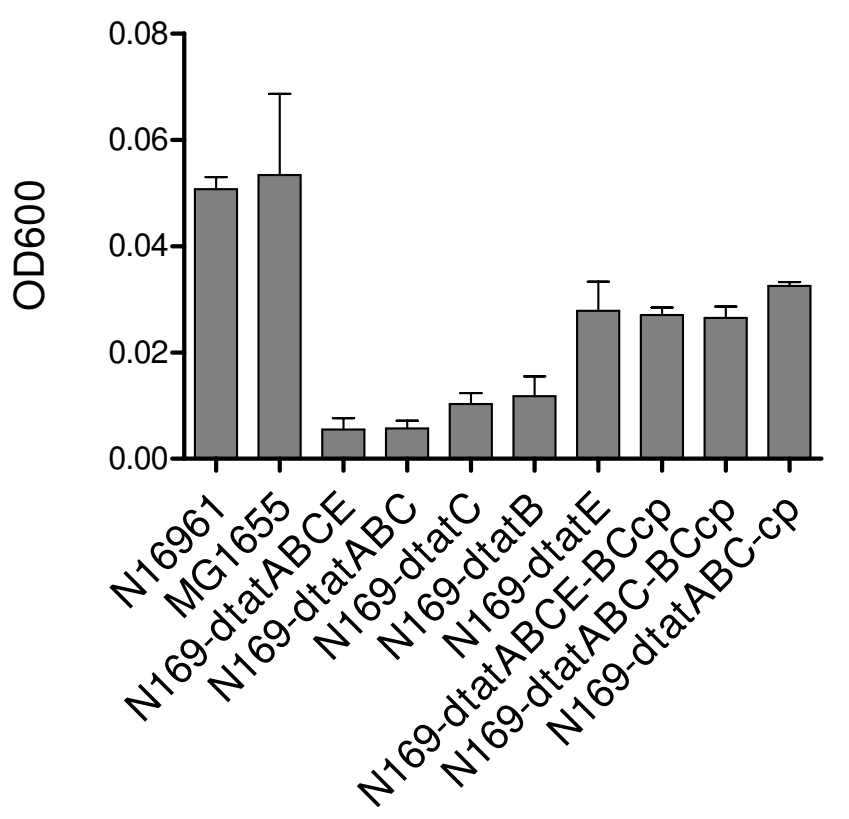

Figure 2

Growth of $V$. cholerae tat mutants and complement strains in M9-TMAO media. The $\mathrm{OD}_{600}$ was measured when the strains were cultured at $37^{\circ} \mathrm{C}$ for $24 \mathrm{~h}$. The $\mathrm{OD}_{600}$ value for each strain was the average of three samples.

\section{Flagellum synthesis and motility}

It has been reported that tat mutants lose motility and their flagellum synthesis is impaired [14]. We inspected the motility of $V$. cholerae N169-dtatABC in soft agar and found that the motility rate of the tatABC mutant was about $90 \%$ of that of the wild type strain (Fig. 4C and 4D), indicating that there is no significant influence of the tat mutation on the motility of cells.

To validate whether the tat $A B C$ mutation of $V$. cholerae impacts flagellum synthesis, flagella were extracted from N16961 and N169-dtatABC cells. The purity of the flagellum extracts in HEPES buffers was confirmed by denaturing SDS-PAGE (data not shown). The concentrations of the flagellum extracts from N16961 and N169-dtatABC cells were $1.328 \mu \mathrm{g} / \mathrm{g}$ and $1.303 \mu \mathrm{g} / \mathrm{g}$ of wet weight of bacterial culture, respectively. We did not find any difference in the amount of extracted flagellum protein between the N16961 and N169-dtatABC cells.

Flagella of the mutants were also observed under the electron microscope (Fig. 4B). Using fluorescence microscopy, we discovered that the motility of the Tat mutants was active. These results are consistent with the normal motility of the Tat mutant in minimal motility agar (Fig. $4 \mathrm{C}$ and 4D). Therefore, the Tat system of $V$. cholerae does not seem to influence flagellum synthesis or motility, unlike that of E. coli O157:H7 [14].

\section{Biofilm formation and CT production}

The ability to form biofilm formation is important for environmental survival and is a determining factor of virulence in pathogenic bacteria. To determine biofilm formation for the Tat mutants, we used a crystal violet staining method to quantify the adhering bacteria cultures in 96-well plates. Our findings indicate that under both aerobic and anaerobic conditions, the biofilm formation ability of the Tat mutant distinctly decreased (Fig. 5), which demonstrated that the Tat system of $V$. cholerae may play an important role in biofilm formation.

We also assessed cholera toxin (CT) production, which is secreted via the type II pathway [35-37]. To compare CT secretion of the wild type strain and tat mutants, we quantified CT production in the supernatant of N16961 and N169-dtatABC cells grown under AKI conditions by GM1ELISA. Unexpectedly, the amount of CT secreted into the supernatant by the tat $A B C$ mutant strain was markedly less than that secreted by the wild type strain $(7.3 \mu \mathrm{g} / \mathrm{ml} /$ $\mathrm{OD}_{600}$ for $\mathrm{N} 169-$ dtatABC and $18.1 \mu \mathrm{g} / \mathrm{ml} / \mathrm{OD}_{600}$ for $\mathrm{N} 16961, \mathrm{P}<0.05$ for the comparison of these two strains, One-Way ANOVA: Post Hoc Multiple Comparisons method, Fig. 6). To investigate if the decreased CT production was a consequence of the tat deletion, complementation experiments were also performed. When the mutant was complemented with pBAD24-tatABC, CT production of the N16961-dtatABC-cp strain increased compared to that of the mutant strains, N169-dtatABC and N169-dtatABC(pUC18) $(\mathrm{P}<0.05$ for the N16961-dtatABC-cp/ N16961 comparison, and $\mathrm{P}<0.05$ for the N169-dtatABCcp/N169-dtatABC comparison, One-Way ANOVA: Post Hoc Multiple Comparisons method, Fig. 6), indicating that the decrease in CT production in the supernatant of the mutant may result from a defect in the Tat system.

We also measured the amount of CT in the cytoplasm. The CT concentration in the cytoplasm of both N16961 and N169-dtatABC cells was much lower $\left(<5 \mathrm{ng} / \mathrm{ml} / \mathrm{OD}_{600}\right)$ than that in the culture supernatant $(14-19 \mu \mathrm{g} / \mathrm{ml} /$ $\left.\mathrm{OD}_{600}\right)$, indicating that most of the CT was exported. The percentages of toxin secreted in the wild type strain and the $\operatorname{tat} A B C$ mutant were nearly identical $(99.97 \%$ and 99.93\%, respectively). Although CT was still exported in the mutant, its production was markedly decreased compared to that of the wild type strain.

We then examined CT gene transcription in the tat mutant and wild type strain with quantitative RT-PCR. We determined that, for the $c t x B$ gene, the difference $\Delta \Delta \mathrm{Ct}$ of N169-dtatABC/N16961 was 1.523 with thyA as the internal reference and 1.506 with the $16 \mathrm{~S}$ rDNA gene as the internal reference. Based on $2^{-\Delta \Delta \mathrm{Ct}}$ method, the $c t x B$ gene transcription level of N169-dtatABC was 0.348 times compared to N16961 when using thyA as reference, and 
Table 2: Using M9-TMAO media to detect the function of the Tat system in E. coli Tat mutant strains complemented with plasmids containing $V$. cholerae tat genes

\begin{tabular}{|c|c|c|c|c|}
\hline Strains & pBAD24 & PTatABC-30I & pBAD-TatABC & pBAD-TatE \\
\hline JARVI6A (dtatAE) & $-\mathrm{a}$ & + & + & + \\
\hline MCMTAA(dtatB) & - & + & + & - \\
\hline BILKOA (dtatC) & - & + & + & - \\
\hline $\mathrm{DADEA}(\mathrm{dtat} A B C D E)$ & - & + & + & - \\
\hline
\end{tabular}

a: "-" or "+" means no-growth or successful growth of the strain in TMAO minimal media under anaerobic conditions, respectively.

0.352 times when using 16s-rDNA gene as reference, showing that cholera toxin gene was downregulated in the Tat mutant when compared to the wild type strain.

\section{In vivo colonization and in vitro cell attachment} experiments

Colonization in the host intestine is required for the pathogenicity of $V$. cholerae. To analyze the colonization ability of the tat mutant strain, a suckling mouse intestine model was used in competitive experiments. We found that the colonization ability of the mutant was less than that of the wild type strain, as the colonization competitive ratio of the wild type strain N16961 to the mutant strain N169-dtatABC was 84:1 (from 40 to 120).

Additionally, in the cell culture model, attachment to HT29 was lower for the mutant than for the wild type strain (Fig. 7A to 7D). The attachment competitive ratio for the wild type strain N16961 to the mutant strain N169-dtat$\mathrm{ABC}$ was 39: 1 (from 16 to 49). When the mutant strain was complemented with pTatABC-N16961, the attachment ability was restored (Fig. 7D).

\section{Discussion}

In this study, we determined the functionality of the tat$A B C$ and tatE genes in $V$. cholerae. Our study demonstrates that the Tat functions are associated not only with the virulence of $V$. cholerae but also with its environmental survival. We found that the Tat system is functionally

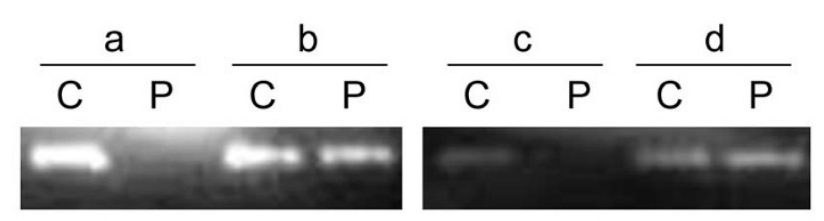

\section{Figure 3}

TMAO reductase detection in both cytoplasm and periplasm by the TMAO enzymatic assay. $C$, cytoplasm; P, periplasm; a, strain NI69-dtatABC; b, strain NI696I; c, strain NI69-dtatABC (pBAD24); d, strain NI69dtatABC-cp. associated with biofilm formation and colonization ability in $V$. cholerae, and it may indirectly affect the production of cholera toxin.

In $E$. coli, tat $A B C$ forms an operon and tatE forms an independent transcriptional unit positioned away from tat$A B C$ [4]. Correspondingly, in V. cholerae strain N16961, tat $A B C$ is located in chromosome $\mathrm{I}$, and tat $E$ is located in chromosome II. By searching the GenBank we found the $\mathrm{O} 1$ classical biotype strain $\mathrm{O} 395$ also possesses tatABC and tatE homologous sequences, we speculate that the toxigenic serogroup $\mathrm{O} 139$ strains should also have the tat gene homologue. Whereas further study is needed to confirm the chromosomal distribution of the genes and functions. It is unclear why $V$. cholerae possesses two chromosomes, perhaps chromosome II plays a specialized independent role under evolutionary selective pres-
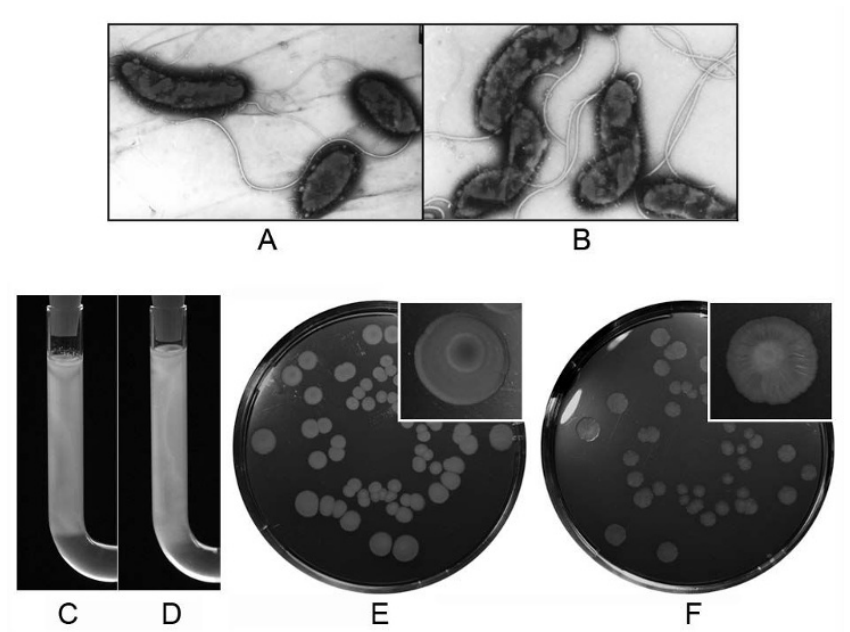

\section{Figure 4}

Phenotypes of the tatABC mutant NI69-dtatABC. A, Electron micrograph of the wild type strain NI696I $(\times 2400)$; $B$, Electron micrograph of the mutant NI69-dtatABC ( $\times 2800)$; C, the motility of NI69-dtatABC in $0.25 \%$ LBA, $37^{\circ} \mathrm{C}, 12 \mathrm{~h}$; D, the motility of $\mathrm{NI} 696 \mathrm{I}$ in $0.25 \% \mathrm{LBA}, 37^{\circ} \mathrm{C}$, $12 \mathrm{~h} ; \mathrm{E}$ and $\mathrm{F}$, Smooth colonies of the wild type strain $(\mathrm{E})$ and rugose colonies of the mutant NI69-dtatABC (F) in LBA after 16 days in room temperature. The magnified inset images show the single colonies. 


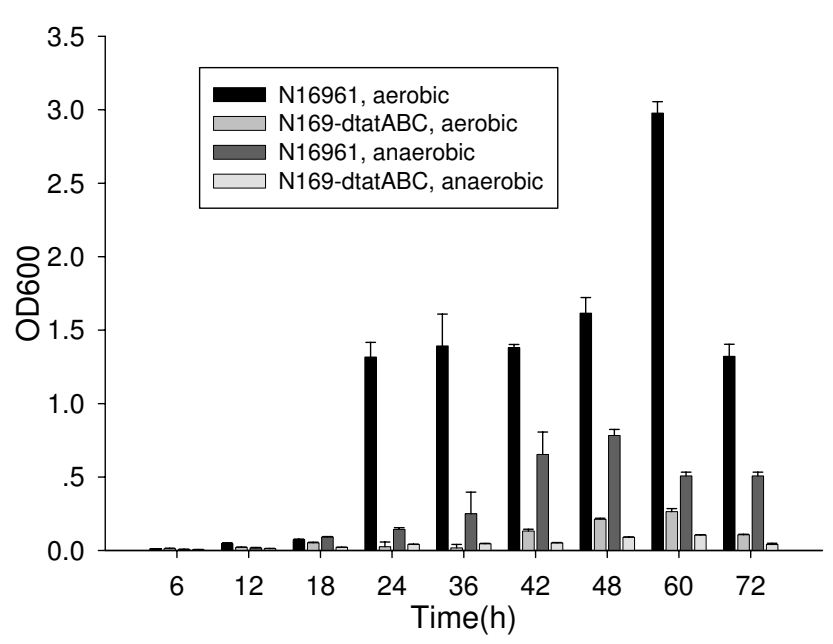

Figure 5

Comparison of biofilm formation by strains NI696 I and NI69-dtatABC cultured under aerobic and anaerobic conditions. For each strain (NI696I and nI69$\mathrm{dtat} A B C$ ), under each condition (aerobic and anaerobic), and at each time point, 7 wells were measured for repeat in one test. And the tests were repeated for three times. T-test was used for the comparison of strains NI696I and NI69-dtat$A B C$ at each time point and under each condition. $P$ values are less than 0.05 in all of the comparisons.

sure [19]. It has been observed that several of the regulatory pathways, for regulation in response to both environmental and pathogenic signals, are divided between the two chromosomes. Also, duplications of genes with at least one of copy of the ORF were found on each chromosome. Most of these genes are involved in $V$. cholerae biology, notably its ability to inhabit diverse environments [19]. Therefore, the function of tatE in particular should be considered. By using reverse transcription PCR, we found that tatE in chromosome II is also transcribed independently (data not shown). It may not be a simple duplication of tatA in chromosome I because individual deficiency of tatA or tatE still impaired the anaerobic growth of mutants in M9-TMAO media in comparison to the wild type strain.

Biofilm formation is crucial for the survival of $V$. cholerae under environmental stress. The formation of biofilm can also make $V$. cholerae more resistant to acidic environments and increase its ability to break through the gastric acid barrier in humans [38]. In this study, we noticed that biofilm formation in the tat $A B C$ mutant was impaired, but it could be restored by complementation with functional tatABC genes. In P. aeruginosa [11] and E. coli [39], biofilm formation of the tat $C$ mutants is also defective. It has been shown that the failure to form biofilms in the $E$. coli tat $C$ mutant strain is due to defects in the cell envelope [39]. Some studies indicate that tat mutant strains display a pleiotropic lesion in their outer membrane $[26,33]$. Based on experiments on the sensitivity of the mutants to the hydrophobic drug Gentamicin and the detergent SDS, we did not find the defects in outer membrane integrity in the $V$. cholerae tat $A B C$ mutant. It is possible that Tat mutations may have pleiotropic effects in different bacteria, that the changed components in the membrane were not detected by our experiments, or that the changed components do not affect the membrane integrity.

Considering that the colonies of the tat $A B C$ mutant can shift to rugose type on LBA after extended time periods, some factors associated with biofilm formation and/or some membrane components are affected in the tat mutant. In comparison with the wild type strain, approximately $50 \%$ of the differentially expressed genes of the $E$. coli tat $C$ mutant are linked to the envelope defect. Many of these genes are involved in self-defense or protection mechanisms, including the production of exopolysaccharides [39].

We found that the $V$. cholerae tat $A B C$ mutant can shift to the rugose phenotype and present "wrinkled" rather than typical smooth colonies on LB agar. In E. coli, tatC mutants routinely appear highly mucoid in comparison with the wild type strain when incubated on solid medium for extended periods of time. This result is thought to be due to the upregulation of some genes related to cell capsule formation in response to the cell envelope defect [39]. Rugose variants secrete copious amounts of exopolysaccharide, which confers resistance to chlorine, acidic $\mathrm{pH}$, serum killing, and osmotic and oxidative stresses. Although the biofilm formation ability of N169-dtatABC decreased within the first three days in liquid culture, the rugose colony transformation capability of the mutant was enhanced when it was cultured at room temperature for longer times. When the rugose colonies of the mutant were transferred to fresh medium, the new colonies shifted exclusively to the smooth phenotype. We deduced that the tat $A B C$ mutant has a decreased ability to adapt to an environment with fewer nutrients in comparison with the wild type strain. Thus, the formation of rugose colonies of the Tat mutant might be a compensation response, which suggests that the Tat system may be involved in the environmental survival of $V$. cholerae.

Colonization in the host intestine is another important virulent factor for $V$. cholerae. We found that tat mutants displayed attenuated colonization competency in suckling mouse intestines and significantly attenuated attachment to HT-29 cells, even when slight differences in culture-growth curves under aerobic and anaerobic conditions were taken into consideration (within 10-fold). Based on these results, we believe that the Tat system may 


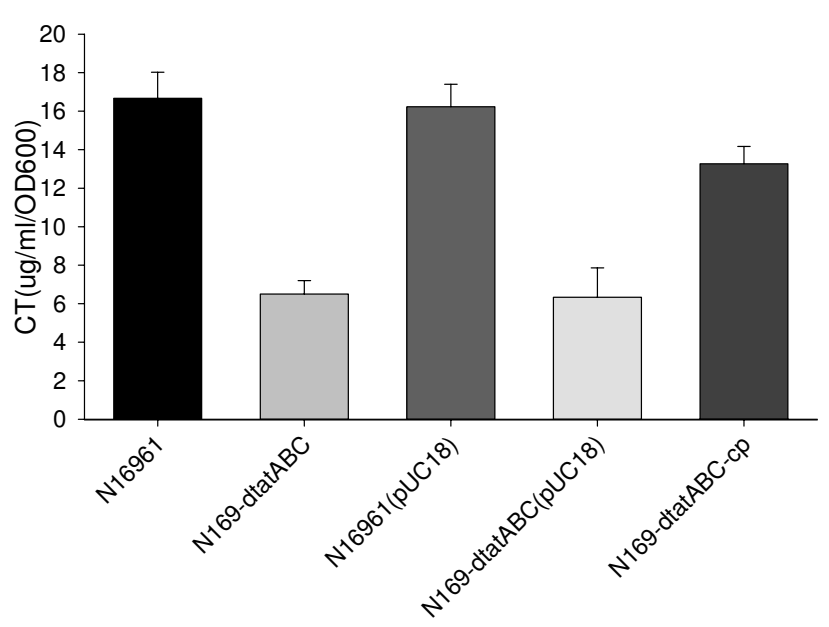

\section{Figure 6}

CT production in the supernatant of strains N1696I, NI69-dtatABC, and NI69-dtatABC-cp. The strains

were cultured using the AKI method. Data were obtained in independent triplicate cultures for each strain.

play a role the in maintenance of attachment and colonization in $V$. cholerae.

Several adherence factors have been described in $V$. cholerae, including outer membrane proteins (i.e., OmpU), hemagglutinins (i.e., mannose-sensitive hemagglutinin, MSHA), pili, and exopolysaccharides. Exopolysaccharides, MSHA and other factors have been proven to affect biofilm formation [40-43]. We speculate that some common factors responsible for adherence and biofilm formation might be affected in the tat mutant of $V$. cholerae, while the direct association might not exist.

Aside from biofilm formation and colonization, cholera toxin is the key virulence factor in the pathogenicity of $V$. cholerae. The activity of this enterotoxin primarily accounts for the clinical manifestations of $V$. cholerae infection. The mature secreted CT is composed of one Asubunit and 5 B-subunits. After translocation through the cytoplasmic membrane via the Sec pathway, the individual toxin subunits assemble noncovalently into an $A_{5}$ holotoxin complex in the periplasm and are then secreted across the outer membrane via the extracellular protein secretion apparatus [35-37]. In our study, we found that the cholera toxin output of the tat $A B C$ mutant strain was less than that of the wild type strain, but the ratio of CT secretion from the cytoplasm into the culture supernatant was the same.

Analysis of $c t x B$ gene transcription revealed a lower level of transcription in the mutant than in the wild type strain. Therefore, the decrease in the amount of CT in the tat $A B C$ mutant may be due to lower production of CT in the mutant. This mechanism appears to differ from the effect of decreased secretion of the Shiga toxin 1 (Stx1) in the tatC mutant of $E$. coli O157:H7, which indicates that Tat may play an important role in secretion or stability of Stx 1 [14]. Considering that the adherence and biofilm formation are also affected in the tat $A B C$ mutant of $V$. cholerae, further study is necessary to determine whether some global regulators responsible for these regulation pathways, their stability in the cytoplasm, or their anchoring in the membrane were affected.

The tat mutants of E. coli O157:H7 [14] and A. tumefaciens [13] lose their mobility, which is correlated with a defect in flagellum biogenesis. A dramatic effect on bacterial motility was also observed in the tat mutant of $P$. aeruginosa. It was presumed that the less motile phenotype was either an indirect effect of abnormal function of the flagella and pili, or the consequence of improper chemotaxis, or both [11]. In our experiments, an effect of flagellum biosynthesis by the tat $A B C$ mutation in $V$. cholerae was not found, and only slightly impaired motility was observed in the $U$ tube tests. These observations illustrate that the effects of Tat may vary in different bacteria. For instance, the tat mutation obviously impairs cell growth rate in normal cultures of A. tumefaciens [13], Mycobacterium smegmatis [44], P. aeruginosa [11], and E. coli [33], whereas it was not affected in the mutants of $Y$. pseudotuberculosis [15] and L. pneumophila [17]. We also did not find a growth difference in LB culture between the tat mutant and the wild strain of $V$. cholerae.

\section{Conclusion}

Our study demonstrates that the Tat system is functionally associated with biofilm formation and colonization ability in $V$. cholerae. In addition, it may indirectly affect the production of the cholera toxin, albeit not through a direct effect on its secretion. Seasonal cholera outbreaks in epidemic areas are linked to the persistence of $V$. cholerae in aquatic ecosystems, providing a reservoir for the initiation of new cholera epidemics via human ingestion of contaminated food or water, once the pathogens have traversed the gastric acid barrier of the stomach and colonized the intestine [45]. The requirement of the Tat system for the maintenance of biofilm formation may play an important role in $V$. cholerae's persistence in aquatic ecosystems. Combined with the findings that a dysfunction in the Tat system can lead to attenuated virulence in other bacteria, Tat can be considered as an important virulence determinant of micropathogens. Therefore, the Tat functions are associated not only with the virulence of $V$. cholerae but also with its environmental survival. Gaining insight into their functionality is an important step in our understanding of the cholera and ultimately in the development of new therapies. 


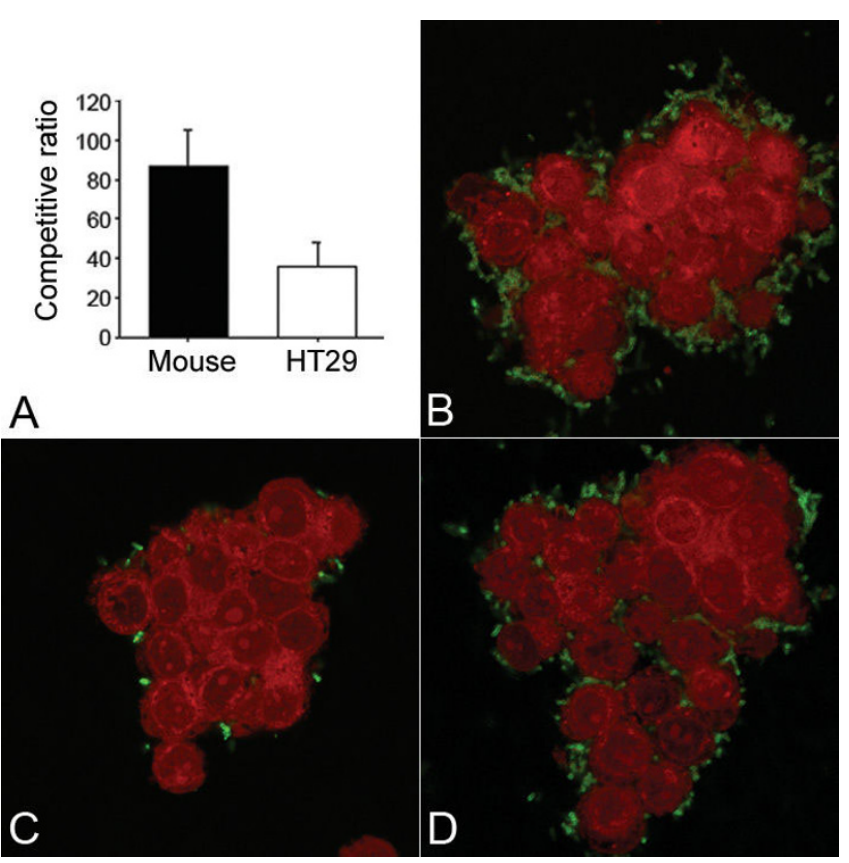

Figure 7

Colonization and attachment attenuation of the tatABC mutant N I 69-dtatABC. A. Colonization competitive ratio in suckling mouse model (left column, from 12 mice) and attachment competitive ratio for HT-29 cells (right column, from 6 repeats); $B$ to $D$, Confocal imaging of the attachment of wild type strain NI696I (B), the tatABC mutant NI69-dtatABC (C), and the complement strain NI69-dtatABC-cP (D) to cultured HT-29 cells. The bacteria (green) were immunostained with FITC-labeled antibodies as described in Materials and Methods. HT-29 cells (red) were identified by Evan's blue staining.

\section{Authors' contributions}

$\mathrm{LZ}$ and $\mathrm{ZZ}$ performed most of the experiments in this study. LZ confirmed the function of tat $A B C$ in $V$. cholerae. $\mathrm{ZZ}$ constructed some new deletion mutants, repeated and complemented the data of the experiments, and prepared the draft. HJ provided plasmids, performed TMAO experiments, and conceived the experiments. JZ performed reverse transcription-PCR and confocal microscopy. YX performed the complementation assay of the E. coli tat gene mutants with the tat genes of $V$. cholerae. MY taught molecular techniques, performed cell culture, and provided critical discussion about the methodology. SG and JX participated in the design and coordination of the study. LF participated in the design and discussion of the study, and also provided E. coli tat mutants. BK designed and coordinated the study, and drafted the manuscript. All the authors read and approved the final manuscript.

\section{Authors' information}

$\mathrm{ZZ}$ now is working in the Research Center of Shanghai Public Health Clinical Center Affiliated to Fudan University.

\section{Additional material}

\section{Additional file 1}

Primers used to construct the recombinant plasmids and mutants of tat genes. In this table the primer sequences used to construct recombinant plasmids, which were applied in construction of the mutants of tat genes, were listed.

Click here for file

[http://www.biomedcentral.com/content/supplementary/14712180-9-114-S1.doc]

\section{Additional file 2}

Localization of $\beta$-lactamase and GroEL in the fractions of $\mathrm{V}$. cholerae strain N16961. The image shows the activity of $\beta$-lactamase and GroEL detected in the fractions of $\mathrm{V}$. cholerae strain N16961, to confirm the periplasmic and cytoplasmic fractions extracted from the whole cells of N16961. The proteins in the fraction of periplasm and cytoplasm were separated by SDS-PAGE and immunoblotted using mouse antibodies to $\beta$ lactamase and GroEL. The sizes of the marker were marked on the left. P: periplasmic fraction. C: cytoplasmic fraction.

Click here for file

[http://www.biomedcentral.com/content/supplementary/14712180-9-114-S2.jpeg]

\section{Acknowledgements}

This work was supported by the National Basic Research Priorities Programme (Grant GI 999054102 and GI999054 I01, Ministry of Science and Technology, P.R. China), and by LSHB-CT-2004-005257. We thank Yinyan Sun for help with confocal microscopy, Qian Zhang for help with reverse transcription-PCR, and Jing Lou for the statistical analysis of the data.

\section{References}

I. Sargent F, Bogsch EG, Stanley NR, Wexler M, Robinson C, Berks BC, Palmer T: Overlapping functions of components of a baterial Sec-independent protein export pathway. EMBO J 1998, 17:3640-3650.

2. Berks BC: A common export pathway for proteins binding complex redox cofactors? Mol Microbiol 1996, 22:393-404.

3. Settles AM, Yonetani A, Baron A, Bush DR, Cline K, Martienssen R Sec-independent protein translocation by the maize Hcf 106 protein. Science 1997, 278:467-70.

4. Berks BC, Sargent F, Palmer T: The Tat protein export pathway. Mol Microbiol 2000, 35:260-274.

5. Muller M: Twin-arginine-specific protein export in Escherichia coli. Res Microbiol 2005, 156:131-136.

6. Palmer T, Berks BC: Moving folded proteins across the bacterial cell membrane. Microbiology 2003, I49:547-556.

7. Alami M, Luke I, Deitermann S, Eisner G, Koch HG, Brunner J, Mûller $M$ : Differential interactions between a twin-arginine signal peptide and its translocase in Escherichia coli. Mol Cell 2003, 12:937-946.

8. Gerard F, Cline K: The thylakoid proton gradient promotes an advanced stage of signal peptide binding deep within the Tat pathway receptor complex. J Biol Chem 2006, 232:5263-5272.

9. Dabney-Smith C, Mori H, Cline K: Oligomers of Tha4 organize at the thylakoid Tat translocase during protein transport. J Biol Chem 2006, 281 : 5476-5483.

10. Gohlke U, Pullan L, McDevitt CA, Porcelli I, Leeuw E, Palmer T, Gouffi K, Gerard F, Santini CL, Wu L-F: Dual topology of the Escherichia coli TatA protein. J Biol Chem 2004, 279:11608-11615.

II. Ochsner UA, Snyder A, Vasil Al, Vasil ML: Effects of the twinarginine translocase on secretion of virulence factors, stress response, and pathogenesis. Proc Natl Acad Sci USA 2002, 99:83।2-83।7.

12. Voulhoux R, Ball G, Ize B, Vasil ML, Lazdunski A, Wu L-F, Filloux A: Involvement of the twin-arginine translocation system in 
protein secretion via the type II pathway. EMBO J 200I, 20:6735-6741.

13. Ding Z, Christie PJ: Agrobacterium tumefaciens twin-arginine dependent translocation is important for virulence, flagellation, and chemotaxis but not type IV secretion. I Bacteriol 2003, I85:760-77I.

14. Pradel N, Ye C-Y, Livrelli V, Xu J-G, Joly B, Wu L-F: Contribution of the Twin arginine translocation system to the virulence of Enterohemorrhagic Escherichia coli O157:H7. Infect Immun 2003, 71:4908-4916.

15. Lavander M, Ericsson SK, Bröms JE, Forsberg Å: The twin arginine translocation system is essential for virulence of Yersinio pseudotuberculosis. Infect Immun 2006, 74: I768-1776.

16. Buck ED, Maes L, Meyen E, Mellaert LV, Geukens N, Anne J, Lammertyn E: Legionella pneumophila Philadelphia-I tatB and tatC affect intracellular replication and biofilm formation. Biochem Biophys Res Commun 2005, 33 I:1413-1420.

17. Rossier O, Cianciotto NP: The Legionella pneumophila tatB gene facilitates secretion of phospholipase $C$, growth under ironlimiting conditions, and intracellular infection. Infect Immun 2005, 73:2020-2032.

18. Angelichio MJ, Merrell DS, Camilli A: Spatiotemporal analysis of acid adaptation-mediated Vibrio cholerae hyperinfectivity. Infect Immun 2004, 72:2405-2407.

19. Heidelberg JF, Eisen JA, Nelson WC, Clayton RA, Gwinn ML, Dodson RJ, Haft DH, Hickey EK, Peterson JD, Umayam L, Gill SR, Nelson KE, Read TD, Tettelin H, Richardson D, Ermolaeva MD, Vamathevan J, Bass S, Qin H, Dragoi I, Sellers P, McDonald L, Utterback T, Fleishmann RD, Nierman WC, White O, Salzberg SL, Smith HO, Colwell RR, Mekalanos JJ, Venter JC, Fraser CM: DNA sequence of both chromosomes of the cholera pathogen Vibrio cholerae. Nature 2000, 406:477-483.

20. Sanchez J, Medina G, Buhse T, Holmgren J, Soberon-Chavez G: Expression of cholera toxin under non-AKI conditions in Vibrio cholerae El Tor induced by increasing the exposed surface of cultures. J Bacteriol 2004, | 86: |355-|36|.

21. Donnenberg MS, Kaper JB: Construction of an eae deletion mutant of enteropathogenic Escherichia coli by using a positive-selection suicide vector. Infect Immun 1991, 59:4310-4317.

22. Philippe N, Alcaraz JP, Coursange E, Geiselmann J, Schneidera D: Improvement of pCVD442, a suicide plasmid for gene allele exchange in bacteria. Plasmid 2004, 5 I:246-255.

23. Khlebnikov A, Risa O, Skaug T, Carrier TA, Keasling JD: Regulatable arabinose-inducible gene expression system with consistent control in all cells of a culture. J Bacteriol 2000, 182:7029-7034.

24. Osborn MJ, Grander JE, Parisi E: Mechanism of assembly of the outer membrane of Salmonella typhimurium. J Biol Chem 1972, 247:3973-3986.

25. Santini CL, Ize B, Chanal A, Muller M, Giordano G, Wu L-F: A novel Sec-independent periplasmic protein translocation pathway in Escherichia coli. EMBO J 1998, I7:101-II2.

26. Ize B, Stanley NR, Buchanan G, Palmer T: Role of the Escherichia coli Tat pathway in outer membrane integrity. Mol Microbiol 2003, 48: $1183-1193$.

27. Loo CY, Corliss DA, Ganeshkumar N: Streptococcus gordonii biofilm formation: identification of genes that code for biofilm phenotypes. J Bacteriol 2000, 182:1374-1382.

28. Benitez JA, Spelbrink RG, Silva A, Phillips TE, Stanley CM, BoesmanFinkelstein M, Finkelstein RA: Adherence of Vibrio cholerae to cultured differentiated human intestinal cells: an in vitro colonization model. Infect Immun 1997, 65:3474-3477.

29. Baselski VS, Parker CD: Intestinal distribution of Vibrio cholerae in orally infected infant mice: kinetics of recovery of radiolabel and viable cells. Infect Immun 1978, 21:5।8-525.

30. Dubey RS, Lindblad M, Holmgren J: Purification of EI Tor cholera enterotoxins and comparisons with classical toxin. J Ren Microbiol 1990, 136:1839-47.

31. Wu L-F, Ize B, Chanal A, Quentin Y, Fichant G: Bacterial twinarginine signal peptide-dependent protein translocation pathway: evolution and mechanism. J Mol Microbiol Biotech 2000, 2:179-189.

32. Bogsch EG, Sangent F, Stanley NR, Berks BC, Robinson C, Palmer T: An essential component of a novel bacterial protein export system with homologues in plastids and mitochondria. J Biol Chem 1998, 273:18003-18006.
33. Stanley NR, Findlay K, Berks BC, Palmer T: Escherichia coli strains blocked in Tat-dependent protein export exhibit pleiotropic defects in the cell envelope. J Bacteriol 200I, 183:139-I44.

34. Chanal A, Santini CL, Wu L-F: Specific inhibition of the translocation of a subset of Escherichia coli TAT substrates by the TorA signal peptide. J Mol Biol 2003, 327:563-570.

35. Ali A, Johnson JA, Franco AA, Metzger DJ, Connell TD, Morris JG Jr, Sozhamannan S: Mutations in the extracellular protein secretion pathway genes (eps) interfere with rugose polysaccharide production in and motility of Vibrio cholerae. Infect Immun 2000, 68:1967-1974.

36. Connell TD, Metzger DJ, Wang M, Jobling MG, Holmes RK: Initia studies of the structural signal for extracellular transport of cholera toxin and other proteins recognized by Vibrio cholerae. Infect Immun 1995, 63:409I-4098.

37. Sandkvist M: Type II secretion and pathogenesis. Infect Immun 200I, 69:3523-3535.

38. Zhu J, Mekalanos J]: Quorum sensing-dependent biofilms enhance colonization in Vibrio cholerae. Dev Cell 2003, 5:647-656.

39. Ize B, Porcelli I, Lucchini S, Hinton JC, Berks BC, Palmer T: Novel Phenotypes of Escherichia coli tat mutants revealed by global gene expression and phenotypic analysis. J Biol Chem 2004, 279:47543-47554.

40. Ghose AC: Adherence and colonization properties of Vibrio cholerae and diarrhoeagenic Escherichia coli. J Med Res Indian 1996, 104:38-51.

4I. Heithoff DM, Mahan MJ: Vibrio cholerae biofilms: Stuck between a rock and a hard place. I Bacteriol 2004, I 86:4835-4837.

42. Sperandio V, Giron JA, Silveira WD, Kaper JB: The OmpU outer membrane protein, a potential adherence factor of Vibrio cholerae. Infect Immun 1995, 63:4433-4438.

43. Taylor RK: Bacterial adhesion to mucosal surfaces. J Chemother 1991, 3: 190-195.

44. Posey JE, Shinnick TM, Quinn FD: Characterization of the twinarginine translocase secretion system of Mycobacterium smegmatis. J Bacteriol 2006, I 88: I332-1340.

45. Lipp EK, Huq A, Colwell RR: Effects of global climate on infectious disease: the cholera model. Clin Microbiol Rev 2002 I 5:757-770.

\section{Publish with Bio Med Central and every scientist can read your work free of charge}

"BioMed Central will be the most significant development for disseminating the results of biomedical research in our lifetime. "

Sir Paul Nurse, Cancer Research UK

Your research papers will be:

- available free of charge to the entire biomedical community

- peer reviewed and published immediately upon acceptance

- cited in PubMed and archived on PubMed Central

- yours - you keep the copyright
BioMedcentral 